\title{
Cervical Cancer Incidence Rates in Texas Counties 1995-2015
}

\author{
Nicholas Salas ${ }^{1 *}$
}

\begin{abstract}
As of 2014, Texas has the 6th highest incidence rate and the 5th highest mortality rate of cervical cancer in the nation. In addition, Texas ranks 3rd to last in the United States in human papilloma (HPV) vaccinations, which helps prevent one of the leading causes of cervical cancer. Cervical cancer incidence rates in Texas remain high, despite it becoming one the most successfully preventable treatable cancers in the United States due to a combination of screenings and HPV vaccinations. Furthermore, spatial distribution of cervical cancer is unknown among Texas counties. This study will follow the political ecology model to elaborate on the political, historical, social, and economic factors that may explain why HPV vaccinations are low and the incidence rate remains high despite the interventions available to people in Texas. This study will examine the geography of cervical cancer in Texas counties from 1995 - 2015 as well as its relationship with religious adherence, socioeconomic status, race/ethnicity, and uninsured rates. I will use a bivariate correlation to relate these factors with cancer incidence rates and ArcMap to create maps to illustrate the spatial distribution of these diseases. The data will be obtained from the Texas Cancer Registry, Texas County Health Rankings 2018, and the Association of Religion Data (CDC) Archives (ARDA). I expect that cervical cancer rates will decline after the introduction of the HPV vaccine in 2007, but areas with higher religious adherence will have higher rates of cervical cancer. In addition, I expect that uninsured rates, race/ethnicity, and socioeconomic factors could possibly impact cervical cancer incidence rates.
\end{abstract}

\section{Keywords}

Human Papilloma Virus (HPV) - Cervical Cancer - Texas

${ }^{1}$ College of Health and Public Service, University of North Texas

${ }^{\star}$ Faculty Mentor: Dr. Joseph Oppong

\section{Contents}

\section{Background}

1.1 The HPV Vaccine

1.2 Religious Adherence

1.3 Socioeconomic Status

1.4 Race and Ethnicity

1.5 Uninsured Rates.

2 Research Hypotheses

3 Methods

4 Results

4.1 Religious Adherence

4.2 Uninsured Rates.

4.3 Education

4.4 Race/Ethnicity

5 Discussion

6 Limitations

7 Conclusion

Author Biography
References

8

\section{Background}

Cervical cancer in western countries is highly preventable due to screenings and a vaccine. Even when diagnosed with cervical cancer, if found early, it is treatable and is associated with long-term survival. However, Texas has some of highest rates of cervical cancer in the United States. Previous research identifies several factors associated with increased prevalence. These are discussed below.

\subsection{The HPV Vaccine}

Cervical cancer is the most common HPV related disease. Furthermore, HPV has been attributed to other cancers of the vagina, penis, anus, rectum, and even the oropharynx.[1, 2, 3] According to Centers for Disease Control and Prevention (CDC), HPV is one of the most commonly sexually transmitted infections (STIs) in the United States.[4] In fact, 90\% of men and $80 \%$ of women that are sexually active will become infected by at least one type of HPV at some point in their lives. [5] HPV falls into two categories, low-risk and high-risk HPVs. Low-risk HPVs tend to cause skin warts around the 
genitals and anus and do not cause cancer. High-risk HPVs can potentially cause cancer and about half of HPV infections are high-risk.[5, 4] Most high-risk HPVs lack symptoms and often go away within 1-2 years however, the infections that persist can lead to cell changes that could develop to cancer. In 2007, the United States Food and Drug Administration (FDA) approved the HPV vaccine for public use.[3] The current vaccines have been known to protect teens and young adults from contracting high-risk HPVs that cause the aforementioned cancers and the spread of HPV. It is suggested that 2 doses of the HPV vaccine are taken for maximum protection. [5, 4]

In the United States, cervical cancer incidence rates have declined, but this is mainly due to effective cervical cancer screenings.[2] However, there is potential to reduce the incidence rate even more with widespread vaccination. For example, Australia offers free vaccinations for girls and young women under the age of 26. As a result, the HPV rate among women aged $18-24$ has dropped from $22.7 \%$ to $1.1 \%$ between 2005 and 2015.[6] This also has led to a herd protection in males.[7] In addition, this has allowed diagnosis of HPV caused genital warts among young women to decline by $59 \%$ and helps reduce the amount of precancerous conditions that could lead to cervical cancer.[8] Another instance is in Rhode Island, where it was recently mandated that 7 th grade students be vaccinated with the HPV vaccine. This would result in over $90 \%$ of Rhode Island teenagers to be vaccinated against HPV.[9] In addition, over $70 \%$ of females and $68 \%$ of males completed the 3 doses recommended by CDC. It is still too soon to determine the impact on cervical cancer rates in Rhode Island, but it is a promising start to stop the spread of HPV, which is the cause of almost all cervical cancers.

\subsection{Religious Adherence}

Vaccines are one of the most important and successful public heath interventions. It has saved countless lives worldwide and minimized or eliminated outbreaks of certain diseases. However, there are people that may pursue a religious exemption for themselves or their child. As a result, this may lead to outbreaks of vaccine preventable diseases.[10]

Texas has one of the higher incidence rates of cervical cancer in the nation with rate of 9.2 per 100,000, when compared to the national average of 7.5 per 100,000.[11] Texas does not mandate HPV vaccinations and ranks 47th in the nation with up to date HPV vaccinations among adolescents.[8] In addition, less than half of Texas adolescents have received one HPV vaccine, while one third were up to date in the year 2016. Originally, Texas did mandate the HPV vaccine when it was first introduced by then governor Rick Perry, however it was soon struck down by the Texas legislature. Why were they so fervently against what is essentially a vaccine for certain cancers? First and foremost, Texas is a very religious state with about $77 \%$ of the adult population identifying as Christian.[12] Of that $77 \%, 31 \%$ of those Christians are Evangelical Protestant, 23\% Catholic, 13\% Mainline Protestant, $6 \%$ Historically Black Protestant, and $4 \%$ other.
According to Shelton et al, Catholics were three times more likely to vaccinate their daughters than those with no religious affiliation.[13] However, some denominations of Christianity, especially Evangelical Protestants reported negative attitudes and beliefs towards the HPV vaccine. This leads to strong religious convictions that see premarital sex as a taboo. Many conservative Christians viewed the HPV vaccine to promote promiscuity among young girls, or provide a "license for sex" as others would say.[14, 13] They also believed that it would send mixed messages to their children. Advocates argue that "their children should receive clear and consistent messages that abstinence is the only responsible, effective, and supported behavior concerning protecting one's sexual health," and nothing else should be used. Ultimately, these parents want their children to follow their religious beliefs, and under those circumstances, may not vaccinate their child. As a result, affiliation with any denominational branch of Christianity, other than Catholicism, may correlate with religious exemption from vaccinations and increased cervical cancer incidence rates.[15]

\subsection{Socioeconomic Status}

Socioeconomic status (SES) is the total measure of an individual's social position in relation to income, education, occupation, etc. According to Oreopoulos and Salvanes, there are massive benefits to be had in obtaining an education, over and above increased income. One benefit is better health outcomes.[16] Low SES groups often act in ways that harm their health and have less access to health care and preventative methods, such as screenings or vaccines, to protect their health. In addition, knowledge of HPV is low or non-existent in most populations of the USA, especially among minorities, populations of low SES and low education levels.[16, 17] Disparities in cervical cancer survival also have persisted according to Lin and colleagues, especially among African American women and those with lower SES in Texas.[18] Thus, SES measured by education level may be related to cervical cancer rates in Texas.

\subsection{Race and Ethnicity}

In the United States, racial and ethnic minorities are often disproportionately impacted by a variety of diseases including cervical cancer. According to the American Cancer Society, Hispanic women are most likely to get cervical cancer, followed by African Americans, Asians, Pacific Islanders, and finally whites.[5] This can be troubling especially in Texas where about $39 \%$ of the population is Hispanic and $12 \%$ is African American.[19] In a Hispanic marriage, it is ideally based on trust, fidelity, and intimacy. Because of this, condom use is often contrary to their ideals and they were reluctant to use them. This would result in higher risk of STIs.[20, 6] Furthermore, many Hispanics believe in some form of fatalism, or pre-determinism, which may cause them to be reluctant to receive care for any disease.[20] 


\subsection{Uninsured Rates}

Lastly, the uninsured are also less likely to get regular vaccinations and health screenings.[21] The U.S. Census Bureau reports that over 5 million Texans lacked health insurance in 2014. The Affordable Care Act (ACA) expanded Medicaid/Medicare and helped lower the uninsured rate in the United States. Under the expansion, families of four who had made an income under 138 percent of poverty level, about $\$ 33,500$, would be eligible. Unfortunately, Texas did not accept the expansion of Medicaid/Medicare under the Affordable Care Act. Thus, people in families with an income below $200 \%$ of the poverty level have a higher likelihood of lacking health insurance.[22] In addition, racial and ethnicity disparities exist in access to health insurance. In Texas, minorities are more likely to go without health insurance than whites. About 59\% of Hispanics/Latinos were uninsured compared to 27\% of whites in 2014.[21] Furthermore, there is a particular challenge to enroll people that are eligible for coverage. Texas did not opt to create an in-person assistance program which becomes problematic especially for Latinos who comprise nearly half of Texas's low-income population.[22] In addition, education also has a relationship with insurance rates. People who have higher education also tend to earn more money and have health insurance coverage.[16,21] Texas has some of the lower rates of high school and college graduates in the United States and these rates tend to be higher among minorities and citizens not born in the United States. As a result of the lack of coverage, these Texans are less able to receive regular and preventative care. These areas that have higher poverty levels tend to be along the Texas-Mexican border, eastern Texas, and in the panhandle and are likely to have a larger population that is uninsured, which may result in higher chances of being diagnosed with cervical cancer.

\section{Research Hypotheses}

Hypothesis 1: Religious adherence in Texas counties may be a factor in cervical cancer incidence rates. Counties with higher Evangelical Protestant adherence rates will have higher cervical cancer incidence rates than those with lower adherence rates.

Hypothesis 2: SES is a factor in cervical cancer rates in Texas counties. Measured by those who have some college education, counties with higher percentage of college education will have lower rates of cervical cancer.

Hypothesis 3: Minorities, especially Hispanic and Black populations are expected to have higher cancer rates. Thus, Texas counties with higher minority populations will have higher rates of cervical cancer.

Hypothesis 4: Being insured is a factor in cervical cancer incidence rates. Those counties with a higher uninsured population will have higher rates of cervical cancer.

\section{Methods}

In this analysis, cervical cancer incidence was defined as age adjusted rate per 100,000 from 1995-2015. This data was gathered from the Texas Cancer Registry. Religious adherence rates were obtained from the Association of Religion Data Archives (ARDA) provided by the Association of Statisticians of American Religious Bodies (ASARB) at the county level. The rest of the data (the percentage of race/ethnicities populations, the percentage of uninsured, and the percentage of those with some college) was gathered from the Texas County Health Rankings 2018.

The Pearson correlation was used to examine the relationship between cervical cancer rate and the several variables that was mentioned prior. Only three ethnic groups were used (non-Hispanic White, Hispanic, and African American). These statistical methods were measured at a .01 significance level.

ArcGIS was used to map the spatial distribution of cervical cancer rates in Texas counties, as well as Evangelical adherence rates, and variables that was a significant factor.

\section{Results}

Figure 1 illustrates the geography of cervical cancer incidence rates in Texas. The state rate is 10.3 per 100,000. The higher rates of cervical cancer incidences are concentrated near eastern, and southern Texas regions with some areas scattered throughout the Great Plains, west Texas, and the panhandle. Some of the highest incidence rates occur in Duval (23.00), Coleman (21.90), Franklin (20.70), and Reeves (19.50) which are well above the state rate. There is also a small cluster in eastern Texas that has high rates. This cluster, highlighted in figure 2 as the black circle, includes San Jacinto (18.40), Trinity (14.90), Walker (17.70), Houston (15.40), and Angelina (15.40). Another small cluster occurs in southeast Texas near the gulf coast. Some counties within the orange transparent circle are Matagorda (16.30), Jackson (17.10), Victoria (14.10), and Calhoun (13.90). Following along the Rio Grande or the border with Mexico, there are also higher rates of cervical cancer. These counties, such as Maverick (15.80), Dimmit (17.7), Willacy (14.00), and Duval (23.00) are highlighted by a gray rectangle in figure 2 . Some of the lower cases occur in north central Texas, for example, Denton (6.80), Tarrant (8.40), Collin (5.60), and Wise (6.80) counties which is highlighted with the blue circle in figure two as well. Unfortunately, there are many counties in the western and Great Plains areas of Texas where there is suppressed or no data available.

In addition, I looked to see if there were any major changes through time, especially when the HPV vaccine was approved for human use. The HPV vaccine was introduced in 2007, so I compared the pre-HPV vaccine period (1995-2006) and post-HPV vaccine period (2007-2015). Figure 2 compares the two time periods. The state rate for the post-HPV vaccine has lowered from 11.1 to 9.3 per 100,000. The highest rate in the 


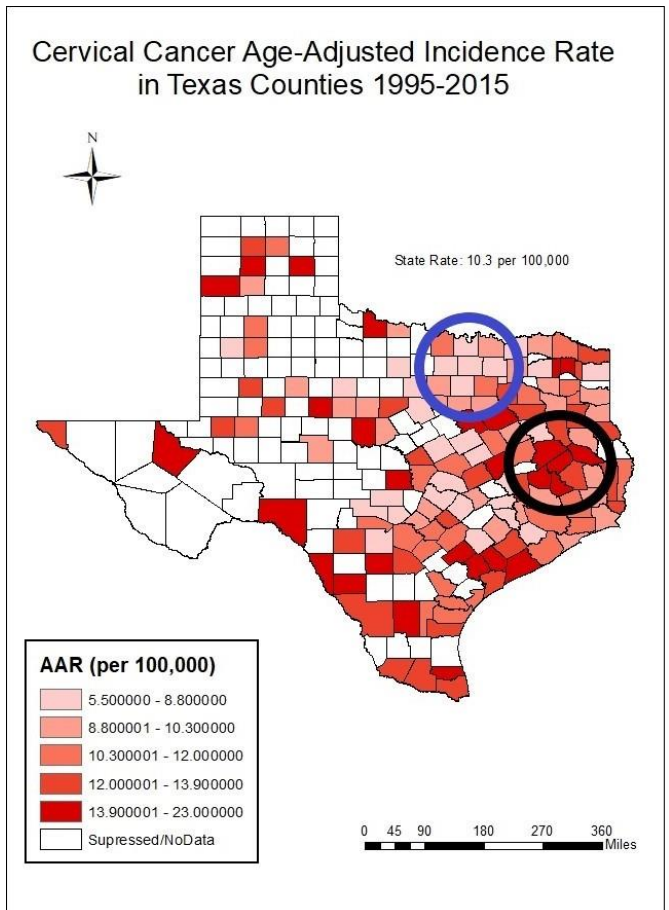

Figure 1. Highlighted Regions: Cervical Cancer Incidence

post-HPV vaccine map is Lampasas (18.5) compared to Duval (27.9) in the pre-HPV vaccine period. So, it is not wrong to say that cervical cancer incidence has decreased slightly over the years. Vaccinations may be a major factor in the decrease of cervical cancer incidence rates in Texas, however other methods such as preventative screenings are a factor. Many counties decreased in incidence rates such as Walker $(-11.7)$, Cherokee (-6.10), El Paso (-5), and Nacogdoches (-4.50). Wharton (2.30), Brown (4.70), and Cooke (3.90) were a few of the counties that saw an increase in their incidence rates. Table 1 shows the change between the counties that had cervical cancer rates in both time periods. More counties decreased in cervical cancer rates than increased. One interesting thing is that Tarrant County did not decrease nor increase in cervical cancer rates even though it typically has better health rates. In addition, many of the counties that had worse health outcomes are in South and Southeastern Texas where more minorities typically reside.

\subsection{Religious Adherence}

Religious adherence (any affiliation) is not a significant factor in relationship to cervical cancer incidence rates $(r=$ $.089, p<.287)$. Thus as religious adherence increases, rates of cervical cancer only slightly increase. Although this relationship was not significant, it is trending in the general direction that the literature suggested. Religion may be an influence, but it probably is not a deciding factor when choosing
Table 1. Pearson Correlations: Cervical Cancer Incidence and SES Factors

\begin{tabular}{lll}
\hline Variable & Coefficient & Significance \\
\hline Religion & 0.089 & 0.287 \\
Percent Evangelical & -0.55 & 0.506 \\
Percent Uninsured & 0.282 & $0.001^{* * *}$ \\
Percent Some College & -0.418 & $0.000^{* * *}$ \\
Percent African American & -0.600 & 0.474 \\
Percent Hispanic & 0.258 & $0.002^{* *}$ \\
Percent Non-Hispanic & -0.235 & $0.004^{* *}$ \\
\hline
\end{tabular}

to vaccinate oneself or their children.

However, I also tested religious adherence rates of Evangelical Protestants to see if the relationship would be any stronger. The relationship had an inverse, weak correlation with cervical cancer rates $(r=-.055, p<.506)$. This correlation is insignificant as well.

\subsection{Uninsured Rates}

Uninsured rates are shown to be significant factors in the relationship to cervical cancer incidence rates $(r=0.282, p<$ $.001)$. Counties with higher rates of uninsured people also tend to have higher rates of cervical cancer incidence rates. People that are uninsured may not get the preventative measures they need to prevent cervical cancer, such as screenings or the HPV vaccine.

Figure 4 illustrates the geography of the percentage of uninsured in Texas. Some clusters that have higher percentages of uninsured are in the Panhandle, western Texas, southern Texas along the border, central Texas, and some of eastern Texas. Lower percentages are clustered in the Great Plains, Austin, and San Antonio areas. The black circles indicate areas that have higher percentages of uninsured and also have higher cervical cancer. For example, Reeves (22\%) and Val Verde $(22 \%)$ in western Texas, Starr $(31 \%)$ by the border in South Texas, Polk (23\%), Angelina (22\%), and Trinity (22\%) counties in south eastern Texas. In these areas, there are also higher percentages of minorities, who typically have higher uninsured rates. In the panhandle of Texas there is also a small cluster, Potter (24\%) and Moore (27\%) counties, which also have higher rates of cervical cancer.

\subsection{Education}

The variable was shown to be significant $(r=-.418, p<$ .000) which means that counties with a higher percentage of those who have some college education also tend to have lower cancer incidence rates.

Texas has a state rate of $60.4 \%$ of adults who have had some college education. This can be important because it is in line with the idea that those who have more education tend to have higher paying jobs, make better choices, and have better health outcomes. Figure 5 demonstrates the geographic distribution of the percentage of those with some college in Texas counties. In south Texas, near the border of Mexico, 


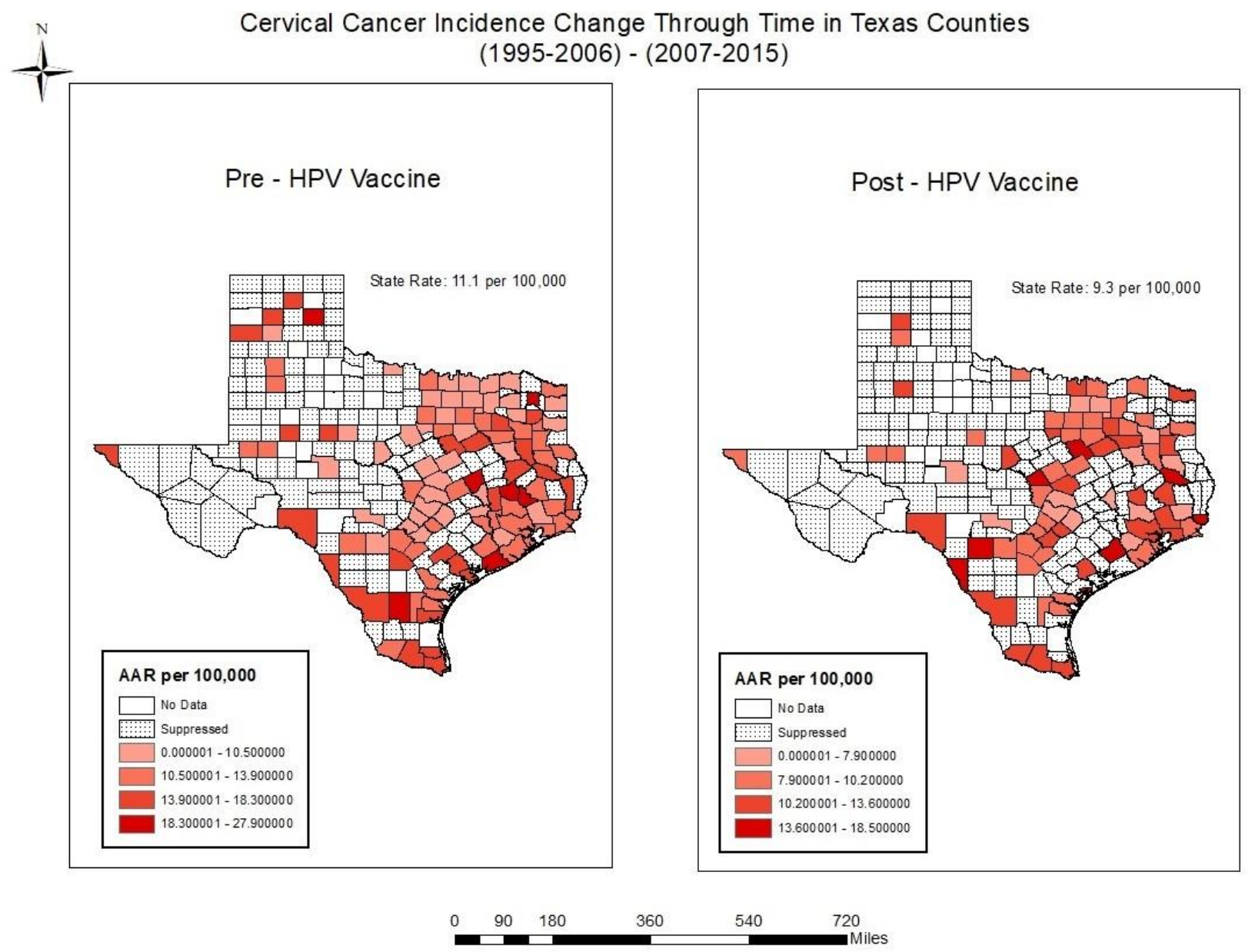

Figure 2. Cervical Cancer Incidence Change, Texas, 1995-2005

counties such as Starr (32\%), Hidalgo (47.1\%), and Willacy $(31.5 \%)$, and in southeastern Texas counties, such as Liberty (37.9), San Jacinto (36.3), and Tyler (38\%) have some of the lower percentages of having some college education and higher cervical cancer rates. These areas are encircled in black. The red circle shows two counties, Tarrant (62.4\%) and Parker (64.6\%), with higher percentages of some college education. These counties also have some of the lower rates of cervical cancer.

What was interesting was that some areas in the panhandle encircled in white, have higher rates of education, but also had higher rates of cervical cancer. This circle includes the counties Randall (72.3\%), Potter (48.6\%), Carson (72.9\%), and Hutchinson (59.3\%). This area illustrates that there must be other factors that impact cervical cancer rates. Ultimately, education could potentially play a part in cervical cancer rates, although other factors may come into play with these percentages such as population size, race/ethnicity, and location of colleges.

\subsection{Race/Ethnicity}

The test returned that there is a significant correlation between the two variables $(r=-235, p<.004)$. When there is a higher white population there tends to be slightly decreased rates of cervical cancer in these counties. This is plausible because whites often have better access to health care compared to other races.

The spatial distribution of the white population is mostly concentrated in the panhandle, central, north central and parts of eastern Texas. Areas that have lower percentages are along the Rio Grande and southern Texas. Figure 6 shows the distribution of the white population in Texas counties. Some counties that highlight high population areas are encircled in a black ring. For instance, Oldham (78.1\%), Baylor (82\%), Wise (77.3), and Tyler (79.4\%) counties all have high percentages of whites and are much higher than the state rate of $42.6 \%$. However, a lot of the areas that have higher white populations also have suppressed or no data, so it is hard to compare figure 1 to figure 6 visually.

Based on the literature, Hispanics typically have higher rates of cervical cancer in the United States and the corre- 


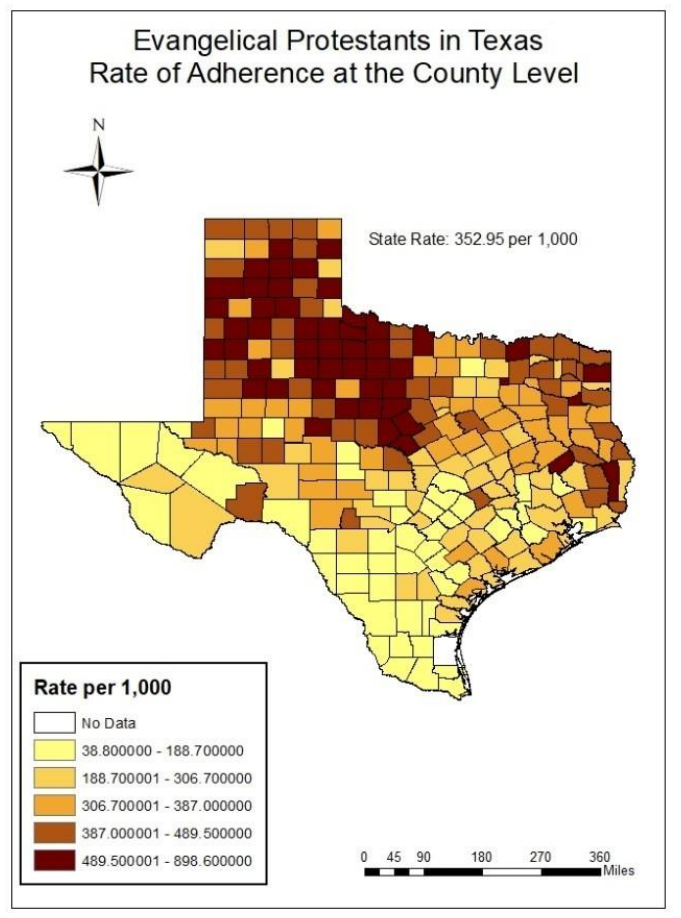

Figure 3. Rate of Adherence: Evangelicals in Texas - 2010 Religious Congregations and Membership Study, ARDA

lation supports that $(r=.258, p<.002)$. This means that as counties with higher percentages are more likely to have slightly higher rates of cervical cancer than those counties with smaller percentages of Hispanics.

Figure 7 illustrates the spatial distribution of Hispanics in Texas counties. Some areas are highlighted with a black circle that show areas with higher percentages of Hispanics. The large populations stretch from western Texas and run along the Rio Grande to South Texas. Presidio (83.8\%), Pecos (68.5\%), Val Verde (81.7\%), Zavala (93.6\%), Zapata (94.6\%), Duval (89.4\%), and Cameron (89.4\%) are some counties in this area. These areas along the border also have some of the higher cervical cancer rates when you compare figure 1 and figure 7 . There are also some high percentages of Hispanics in the panhandle, Parmer (62.7\%) and Castro (64.1\%) counties, for example. In addition, counties near and in the metroplex have some higher Hispanic populations, for instance, Ellis (82.2\%), Denton (34.6\%), Tarrant (28.4\%), and Dallas (39.9\%) counties. Central and eastern Texas have some of the lowest populations of Hispanics in Texas. This includes the counties Newton (3.5\%), Jasper (6.9\%), Polk (14.7\%), Bowie (7.6\%), and Wood (9.7\%). There is a county, La Salle, which sticks out in South Texas. This county is surrounded by large Hispanic populations, but only has a 7\% Hispanic population. This county and some other counties with low

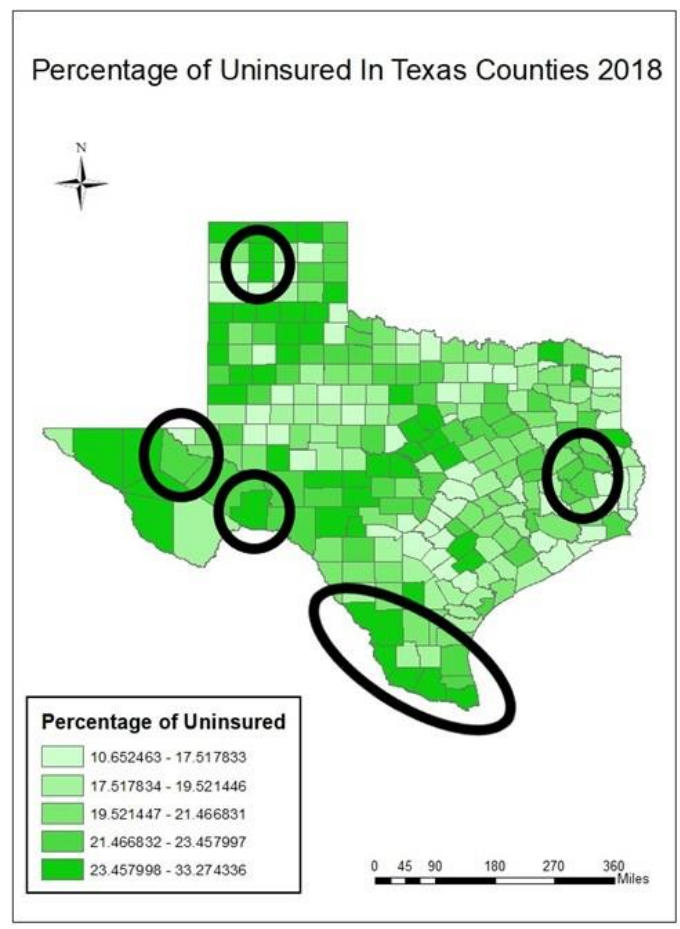

Figure 4. Percentage of Uninsured in Texas Counties 2018 Texas County Health Rankings 2018

areas of Hispanics populations are encircled in red.

The percent African American analysis resulted in a very weak negative correlation $(r=.060, p<.474)$. This is surprising because the literature presents African Americans as having a higher chance of having cervical cancer. So, counties with larger black populations should also tend to have an increase of cervical cancer rates, not a decrease. This could be due to a number of reasons, such as a small numbers problem, lack of data, and smaller African American populations in Texas counties.

\section{Discussion}

HPV vaccination could play a large part in why Texas has one of the highest rates of cervical cancer in the United States. Religious adherence in Texas was used as measure for HPV vaccinations because data for actual vaccinations was not available. As a variable, religious adherence for all religions in Texas did not show a significant correlation, however the trend followed what the literature supported. However, when focusing on the evangelical protestant community, which seemed to disapprove of the HPV vaccine the most, there was a negative correlation. Although it was not a significant factor, the trend was opposite of what was expected. Maybe this could be because I only measured Evangelical Protestants, rather than all Protestants. Furthermore, Evangelical Protestants also tend 
Percent of Populations with Some College Education in Texas Counties 2018

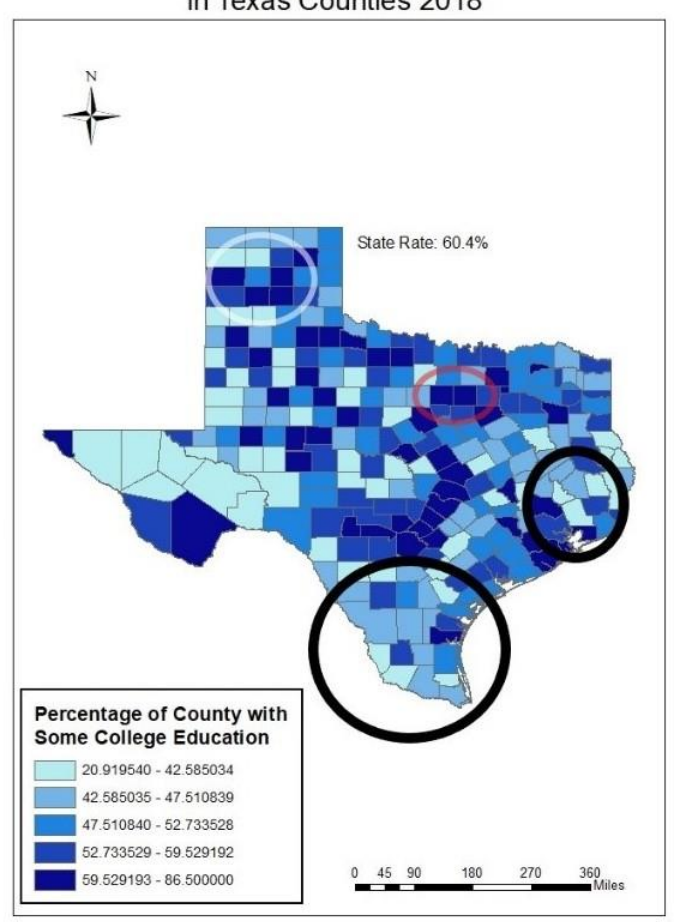

Figure 5. Percent of Those with Some College Education in Texas Counties 2018 - Texas County Health Rankings 2018

to be white, and white populations tend to have better health outcomes. Especially when one compares figure 4 and 7, one can see that it is distributed similarly. So, maybe evangelicals do not get the HPV vaccine, but more of them are able to receive regular screenings that prevent cervical cancer. Because of all of this, religion adherence probably is not an effective measure of HPV vaccination in Texas counties.

Being uninsured, having some college education, and being white or Hispanic were found to have significant correlations with cervical cancer incidence rates. Texas counties with higher percentages of those with some college education also tended to have the lower rates of cervical cancer. This is illustrated in figure 6 . This could be due to the fact that people with higher education often have better income and access to health care. These people are also more informed and will make better health choices, especially seeking out screening and vaccinations. Texas counties that had larger white populations also tended to have lower cervical cancer rates. The literature supports my findings as white populations typically have better health outcomes compared to other races/ethnicities. African American populations did not show a positive trend as was expected. There was not a significant correlation and the trend was negative. This is not what the literature supports, but this could due be to some confounding factor or lack of data at the county level.
Percentage of Non-Hispanic Whites in Texas Counties 2018

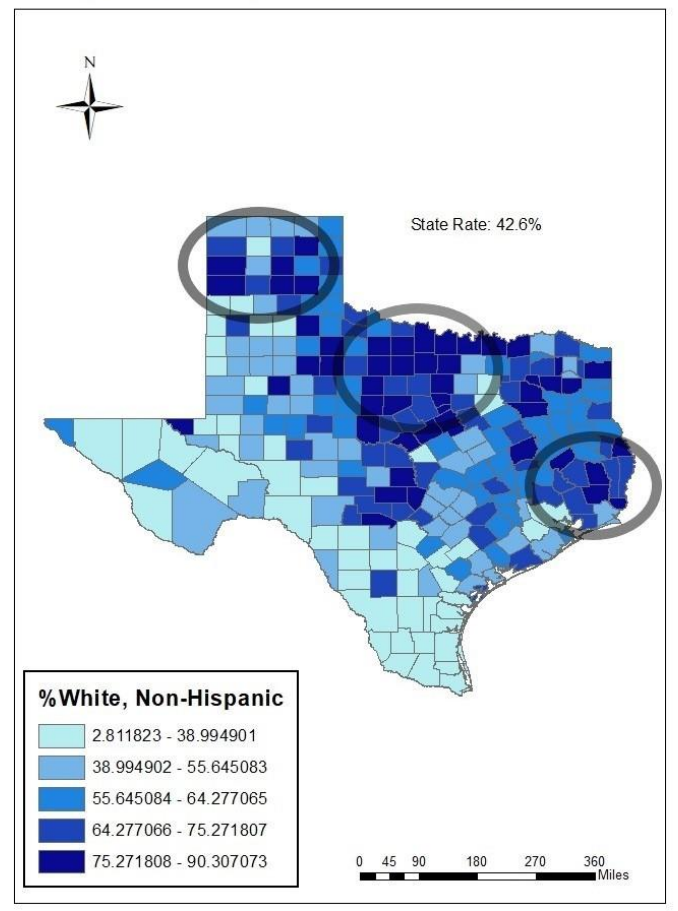

Figure 6. Percentage of Non-Hispanic Whites in Texas Counties 2018 - Texas County Health Rankings 2018

However, those counties with larger uninsured rates tended to have higher cervical cancer incidence rates. This illustrates that people who cannot afford healthcare often probably have to pass on preventative screenings and methods that could improve their health outcomes. Furthermore, it means they are likely not to get vaccinated for HPV, especially because it is not a requirement for their children or themselves. In addition, a county with a larger Hispanic population also had higher cervical cancer incidence rates. The literature supports my findings, as most Hispanics have little to no knowledge of cervical cancer and its link to HPV. This could be largely the reason there is a correlation between the two factors.

\section{Limitations}

There are some limitations in this research. First, the cervical cancer incidence data contained a lot of suppressed data for some counties that was unable to be used because there were not enough cases to calculate a stable age-adjusted rate. So, there may be some stronger or weaker correlations with the different factors that would be seen had there been more data available. There was also a lack of HPV vaccination data. There was little to no data that could provide an accurate measure of vaccination records at the county level, so religion adherence was used as a proxy. The religious adherence correlation could possibly have been stronger had there been 
Percentage of Hispanics in Texas Counties 2018

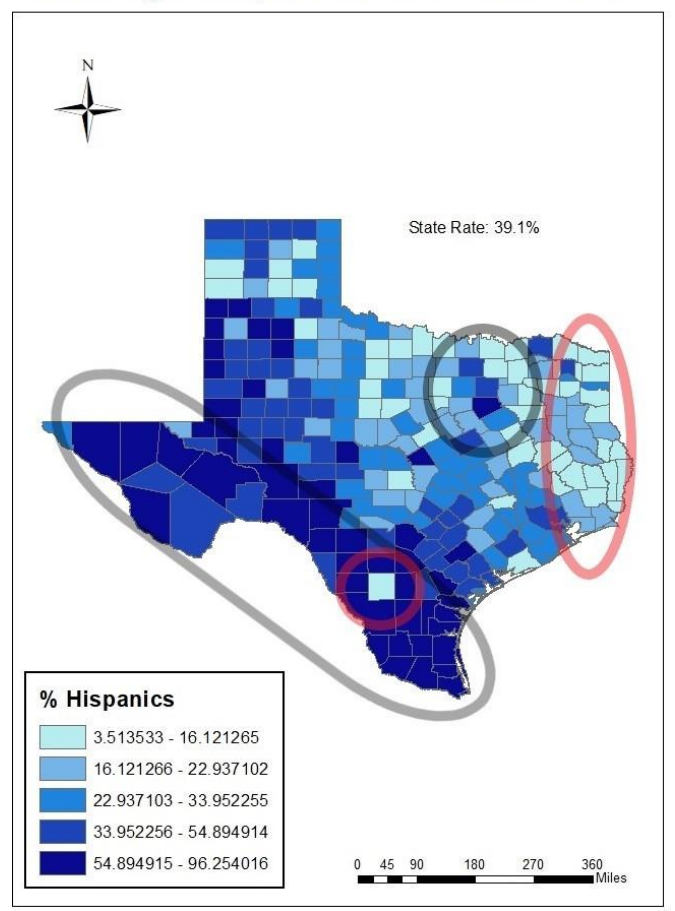

Figure 7. Percentage of Hispanics in Texas Counties 2018 Texas County Health Rankings 2018

data for religious adherence rate for all Protestants rather than just Evangelicals. Unfortunately, lack of data was one of the main problems.

Another limitation is the modifiable areal unit problem or MAUP, a phenomenon that illustrates the need to consider the space in one's analysis, and the uncertainties that accompany real-world analysis.[17] It is the result of artifacts or errors created when one groups data in units for analysis. Grouping the data, as I did with cervical cancer incidence at the county level may distort or exaggerate the actual data pattern. If I were to analyze the data at different levels, such as zip code, census block, public health region, etc., then the analysis would likely produce different results. In addition, when data is grouped like this, it assumes that spatial variation within the unit, the county in this case, is frozen. For example, if there are many cases in a county that occurs only in small area of the unit, then it may imply that the whole county is having that problem rather than that small section. Similarly, if one looks at two adjacent units, it assumes that the distribution of the cases is discrete, rather than continuous among units.

Finally, the intent of this research was to test if there was any possible relationship between the factor and cervical cancer incidence. These results are by no means causative. There are too many confounding factors that may result in higher cervical cancer incidence.

\section{Conclusion}

Cervical cancer incidence rates in Texas are slightly increasing, despite a general downward trend in the United States, and this research was an attempt to see what political, cultural, and other factors may result in this rise, especially in relationship with the low HPV vaccine rates in Texas. Low vaccination rates may be a factor however there is little data available to compare with the distribution of cervical cancer rates at the county level. Religion probably is not a good proxy variable to measure HPV vaccinations, however it may play a small part in one's judgement in getting the vaccine. SES and uninsured rates may be a better variable to measure the people who get the HPV vaccine, because there was a significant relationship with those two factors. Also, it was important to note that percent Hispanic population had a significant relationship with cervical cancer rates. More research should be done involving these significant factors and implement some intervention in areas where there is higher uninsured, higher Hispanic, or lower educated populations.

\section{Author Biography}

Nicholas Salas is from Arlington, Texas. He is studying Public Health with a certification in GIS and is planning on graduating in May 2019. He hopes to work with local health departments, to help improve the health of his community, and maybe work for the CDC one day.

\section{References}

${ }^{[1]}$ CDC. CDC-cervical cancer fact sheet. https : / / www . cdc.gov/cancer/cervical/index.htm. Accessed: 2018-02-09.

[2] CFS. Cancer stat facts: Cervical cancer. https: / / seer.cancer.gov/statfacts / html/cervix.html. Accessed: 2018-03-16.

[3] WHO. Human papillomavirus (HPV) and cervical cancer. http://www. who.int/mediacentre/ factsheets/fs380/en/. Accessed: 2018-02-09.

[4] CDC. Human papillomavirus. https://www. cdc. gov/hpv/. Accessed: 2018-03-21.

[5] NCI. National Cancer Institute: Human papillomavirus (HPV) vaccines. https://www. cancer. gov/about-cancer/causes-prevention/ risk/infectious-agents/ hpv-vaccine-fact-sheet. Accessed: 2018-0321.

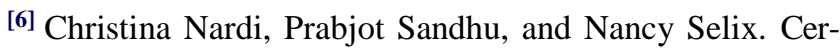
vical cancer screening among minorities in the United States. The Journal for Nurse Practitioners, 12(10):675-682, 2016.

https://doi.org/10.1016/j.nurpra.2016.08.036

${ }^{[7]}$ N. Zhou. Australia could become first country to eradicate cervical cancer. https : / / www . theguardian . 
com/society/2018/mar/04/. Accessed: 201804-12.

[8] Eileen Nehme, Divya Patel, Daniel Oppenheimer, MFA Nagla Elerian, and David Lakey. Missed Opportunity.

[9] J. Bogdan. RI still leads country in hpv vaccination rate. http://www.providencejournal.com/ news/20170908/. Accessed: 2018-04-11.

[10] Emily Oshima Lee, Lindsay Rosenthal, and Gabriel Scheffler. The effect of childhood vaccine exemptions on disease outbreaks. Center for American Progress, 2013.

[11] DHS. United States Cancer Statistics: 1999-2014 Incidence and Mortality. U.S. Department of Health and Human Services, 2017.

[12] PRF. Religious landscape study.

http: //www. pewforum.org/

religious-landscape-study/state/

texas /. Accessed: 2018-04-19.

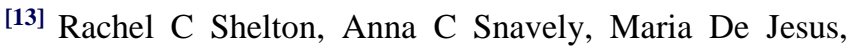
Megan D Othus, and Jennifer D Allen. HPV vaccine decision-making and acceptance: does religion play a role? Journal of Religion and Health, 52(4):1120-1130, 2013.

https://doi.org/10.1007/s10943-011-9553-x

[14] Cheryl A Vamos, Robert J McDermott, and Ellen M Daley. The HPV vaccine: framing the arguments for and against mandatory vaccination of all middle school girls. Journal of School Health, 78(6):302-309, 2008.

https://doi.org/10.1111/j.1746-1561.2008.00306.x

[15] Anna E Strohl, Gricelda Mendoza, Marissa S Ghant, Kenzie A Cameron, Melissa A Simon, Julian C Schink, and Erica E Marsh. Barriers to prevention: knowledge of hpv, cervical cancer, and HPV vaccinations among African American women. American Journal of Obstetrics and Gynecology, 212(1):65-e1, 2015.

https://doi.org/10.1016/j.ajog.2014.06.059

${ }^{[16]}$ Philip Oreopoulos and Kjell G Salvanes. Priceless: The nonpecuniary benefits of schooling. Journal of Economic Perspectives, 25(1):159-84, 2011.

DOI: 10.1257/jep.25.1.159

[17] Daniel Ervin. Maup an introduction to the modifiable areal unit problem. Retrieved from Advanced Spatial Analysis: Learning and research resources for the population sciences: http://gispopsci. org/maup, 2014.

[18] Yan Lin, Mario Schootman, and F Benjamin Zhan. Racial/ethnic, area socioeconomic, and geographic disparities of cervical cancer survival in Texas. Applied Geography, 56:21-28, 2015.

https://doi.org/10.1016/j.apgeog.2014.10.004

[19] USCB. U.S. Census Bureau QuickFacts: Texas. https://www.census.gov/quickfacts/ fact/table/TX/PST045217\#viewtop. Accessed: 2018-04-11.
[20] Maria E Fernandez, Sheryl A McCurdy, Sarah R Arvey, Sandra K Tyson, Daisy Morales-Campos, Belinda Flores,Bernardo Useche, Lisa Mitchell-Bennett, and Maureen Sanderson. HPV knowledge, attitudes, and cultural beliefs among Hispanic men and women living on the Texas-Mexico border. Ethnicity \& Health, 14(6):607-624, 2009.

https://doi.org/10.1080/13557850903248621

[21] TMA. Texas Medical Association: The uninsured in Texas. https://www.texmed.org/ uninsured_in_texas/. Accessed:2018-04-11.

${ }^{[22]}$ Benjamin D Sommers. Medicaid Expansion in Texas: What's at Stake? Commonwealth Fund, 2016. 